\title{
Inhaled corticosteroid therapy in Asthma and Osteoporosis
}

Inhaled corticosteroids (ICS) are widely used in the treatment of asthma but their safety on bone density is controversial. ${ }^{1}$ Bone mineral density (BMD) is assessed by DEXA - dual energy radiologic absorptiometry (osteodensitometry) - performed at the proximal femur and lumbar spine levels. The absolute BMD values and the T-score (femoral neck, total hip and lumbar spine) should be taken into account in postmenopausal women and in men over 50 years of age (T-score $\geq-1$ :normal; $-2.5<\mathrm{T}$-score $<-1$ :osteopenia; T-score $\leq$ 2.5 :osteoporosis). In premenopausal women and men under 50, the Z-score is preferred. The International Society for Clinical Densitometry (ISCD) recommends that a Z-score index less than -2.0 be defined as "below the expected range for age" and a Z-score above -2.0 is "within the expected age range". ${ }^{2}$

A study published by Hamida B et al., without risk factors for osteoporosis, concluded that ICS was safe, not affecting BMD. ${ }^{3}$ On the other hand, Monadi $\mathrm{M}$ et al., reported a significant decrease in BMD in asthmatic patients under 50years old, but not in patients over 50years when treated ICS. ${ }^{4}$ The authors proposed to conduct a prospective study with BMD assessment in asthmatic patients treated with ICS for at least 5years. Exclusion criteria were defined: postmenopausal women, men 65years or older, patients undergoing immunosuppressive therapies, patients with immunodeficiency disorders or cancer. The study included patients seen at the Severe Asthma and Allergology outpatient clinic of Centro Hospital Universitário Coimbra (CHUC), between July and October 2018. The selected patients underwent DEXA at the Nuclear Medicine department of CHUC.

Patient's demographics are referred in Table 1. Of the 14 patients included, 7 are men under 50years of age or women premenopausal

\author{
Volume 7 Issue 3 - 2020
}

\section{Eunice Dias, João Nunes Caldeira, Margarida Pimenta Queiroz Valério, Ana Maria da Fonseca Arrobas Correia de Matos \\ Department of Pneumology, Coimbra Hospital and University Centre - General Hospital, Portugal}

Correspondence: Eunice Dias, Department of Pneumology, Coimbra Hospital and University Centre - General Hospital, Portugal,Tel00351964156812,Email eunicedias@gmail.com Received: September II, 2020 | Published: September 28,
2020

women; the remaining 7 are men over the age of 50. The first group has an average age of $41.4 \pm 4.3$ years and $6(85.7 \%)$ patients are women. The second group, all men, has an average age of $56.1 \pm 1.9$ years. In the first group, asthma has an average duration of $22.4 \pm 10.4$ years and the average duration of ICS treatment is $14.0 \pm 6$.0years. Fluticasone propionate is the most used ICS $(n=4,57.1 \%)$, followed by budesonide $(\mathrm{n}=3,42.9 \%)$. Two patients use high dose fluticasone $(>500 \mu \mathrm{g} /$ day $)$, 2 use medium dose fluticasone $(>250-500 \mu \mathrm{g} /$ day) and 3 patients use low dose budesonide (200-400 $\mu \mathrm{g} /$ day). In the second group, asthma has an average duration of $21.7 \pm 12.2$ years and the average duration of ICS treatment is $21.3 \pm 10.8$ years. Budesonide is the most used ICS $(\mathrm{n}=5,71.4 \%)$, followed by fluticasone propionate $(\mathrm{n}=2,28.6 \%)$. One patient is on high dose budesonide ( $>800 \mu \mathrm{g} /$ day), 1 medium dose budesonide ( $>400-800 \mu \mathrm{g} /$ day), 3 low dose budesonide $(200-400 \mu \mathrm{g} /$ day), 1 high dose fluticasone $(>500 \mu \mathrm{g} /$ day $)$ and 1 patient low dose fluticasone $(100-250 \mu \mathrm{g} / \mathrm{day})$.

Table I Patients demographics

Men $<50$ years of age + premenopausal women (Group I) Men $\geq 50$ years of age (Group 2)

\begin{tabular}{|c|c|c|}
\hline Patients number $(\mathrm{n})$ & 7 & 7 \\
\hline Male/Female $-n(\%)$ & I (14.3\%)/6(85.7\%) & $7(100 \%) / 0$ \\
\hline Mean age $($ mean $\pm S D)$ years & $41.4 \pm 4.3$ years & $56.1 \pm 1.9$ years \\
\hline FEVI of predicted (mean \pm SD) $\%$ & $80.2 \pm 23.1 \%$ & $80.5 \pm 15.9 \%$ \\
\hline Current smoking $-\mathrm{n}(\%)$ & I (I4.3\%) & $2(28.6 \%)$ \\
\hline Asthma (mean $\pm S D)$ & $22.4 \pm 10.4$ years & $21.7 \pm 12.2$ years \\
\hline ICS (mean $\pm S D)$ & $14.0 \pm 6.0$ years & $21.3 \pm 10.8$ years \\
\hline Vitamin D deficiency - n (\%) & $3(42.9 \%)$ & $6(85.7 \%)$ \\
\hline
\end{tabular}


Table Continued...

\begin{tabular}{|c|c|c|c|}
\hline & & Men $<50$ years of age + premenopausal women (Group I) & Men $\geq \mathbf{5 0}$ years of age (Group 2 ) \\
\hline \multirow{3}{*}{ Budesonide } & 200-400ug/day & $3(42.9 \%)$ & $3(42.9 \%)$ \\
\hline & $>400-800$ ug/day & 0 & I (14.3\%) \\
\hline & $>800$ ug/day & 0 & I (I4.3\%) \\
\hline n (\%) & 100-250ug/day & 0 & I (I4.3\%) \\
\hline \multirow[t]{2}{*}{ Fluticasone } & $>250-500$ ug/day & $2(28.6 \%)$ & 0 \\
\hline & $>500$ ug/day & $2(28.6 \%)$ & I (14.3\%) \\
\hline \multicolumn{4}{|l|}{ Lumbar spine } \\
\hline $\mathrm{BMD}($ mean $\pm \mathrm{SD})$ & & $1.039 \pm 0.181 \mathrm{~g} / \mathrm{cm}^{2}$ & $0.852 \pm 0.118 \mathrm{~g} / \mathrm{cm}^{2}$ \\
\hline \multicolumn{2}{|c|}{ T-score $\geq-1:$ normal - n (\%) } & & I (14.3\%) \\
\hline \multicolumn{2}{|c|}{$-2.5<\mathrm{T}$-score $<-$ I :osteopenia - n (\%) } & & $2(28.6 \%)$ \\
\hline \multicolumn{2}{|c|}{ T-score $\leq-2.5$ : osteoporosis - n (\%) } & & $4(57.1 \%)$ \\
\hline \multicolumn{2}{|l|}{ Z-score<-2 - n (\%) } & 0 & \\
\hline \multicolumn{2}{|l|}{ Z-score>-2 - n (\%) } & $7(100 \%)$ & \\
\hline \multicolumn{4}{|l|}{ Femural neck } \\
\hline \multicolumn{2}{|l|}{ BMD (mean $\pm S D)$} & $0.785 \pm 0.127 \mathrm{~g} / \mathrm{cm}^{2}$ & $0.767 \pm 0.108 \mathrm{~g} / \mathrm{cm}^{2}$ \\
\hline \multicolumn{2}{|c|}{ T-score $\geq-$ I: normal - n (\%) } & & 0 \\
\hline \multicolumn{2}{|c|}{$-2.5<$ T-score<- I: osteopenia - n (\%) } & & $4(57.1 \%)$ \\
\hline \multicolumn{2}{|c|}{ T-score $\leq-2.5$ : osteoporosis - $n(\%)$} & & $3(42.9 \%)$ \\
\hline \multicolumn{2}{|l|}{ Z-score<-2 - n (\%) } & 0 & \\
\hline \multicolumn{2}{|l|}{ Z-score>-2 - n (\%) } & 0 & \\
\hline
\end{tabular}

Abbreviations: BMD, bone mineral density; ICS, inhaled corticosteroids; $n$, number of patients; SD, standard deviation

According to the ISCD definition, all patients in the first group have BMD "within the expected age range," with a Z-score above -2.0 , both in the lumbar spine and in the femoral neck (mean BMD in the lumbar spine: $1,039 \pm 0.181 \mathrm{~g} / \mathrm{cm}^{2}$; average BMD in the femoral neck: $\left.0.785 \pm 0.127 \mathrm{~g} / \mathrm{cm}^{2}\right)$. In the second group, $4(57.1 \%)$ patients have osteoporosis in the lumbar spine (mean BMD of $0.779 \pm 0.029 \mathrm{~g}$ / $\left.\mathrm{cm}^{2}\right), 2(28.6 \%)$ patients have osteopenia (mean BMD $0.878 \pm 0.045 \mathrm{~g} /$ $\mathrm{cm}^{2}$ ) and 1 (14.3\%) patient has no changes (BMD 1,090g/ $\left.\mathrm{cm}^{2}\right)$. At the femoral neck level, still in relation to the second group, 4 (57.1\%) patients have osteopenia (BMD $0.696 \pm 0.052 \mathrm{~g} / \mathrm{cm}^{2}$ ) and $3(42.9 \%$ ) patients have no changes (BMD $0.863 \pm 0.081 \mathrm{~g} / \mathrm{cm}^{2}$ ). In our study changes in BMD compatible with osteoporosis and osteopenia were found only in the group of patients over 50years of age. It is worth noting, however, a significant discrepancy between BMD found at the level of the lumbar spine $\left(1,039 \pm 0.181 \mathrm{~g} / \mathrm{cm}^{2}\right)$ compared to BMD at the level of the femoral neck $\left(0.785 \pm 0.127 \mathrm{~g} / \mathrm{cm}^{2}\right)$, in the other group of patients.

Although asthma has a similar average duration in the 2groups, the average duration of treatment with ICS is longer in the second group. As for the ICS used and dosage, the distribution has no significant differences between the two groups and does not seem to be responsible for the findings. In relation to other risk factors for osteoporosis, it is noteworthy that $6(85.7 \%)$ patients in the second group have vitamin $\mathrm{D}$ deficiency, whereas this is only seen in $3(42.9 \%)$ patients in the first group. Risk factors for osteoporosis such as tobacco or low body mass index did not influence BMD. On the other hand, asthma itself can be a risk factor for lower BMD. ${ }^{5}$ Nevertheless, the conclusion regarding the impact of ICS on BMD is limited by the lack of a control group. 


\section{Acknowledgments}

None.

\section{Conflicts of interest}

Authors declare no conflict of interest exists.

\section{Funding}

None.

\section{References}

1. Heffler E, Pizzimenti S, Guida G, et al. Prevalence of over misdiagnosis of asthma in patients referred to an allergy clinic. J Asthma. 2015;52(9):931934.
2. Adult Official Positions of the International Society for Clinical Densitometry. 2019.

3. Hamida B, Krichene N, Amara K, et al. Effect of inhaled corticosteroids on bone mineral density in asthmatic adults: a 20 cases study. Tunis Med. 2011;89(5):434-439.

4. Monadi M, Javadian Y, Cheraghi M, et al. Impact of treatment with inhaled corticosteroids on bone mineral density of patients with asthma: related with age. Osteoporos Int. 2015;26(7):2013-2018.

5. Global Initiative for Asthma (GINA). Global Strategy for Asthma Management and Prevention. 2019. 